\title{
Hepatitis C virus-associated cryoglobulinemia with membrano-proliferative glomerulonephritis treated with prednisolone and interferon: A case report
}

\author{
QIAO-YAN GUO, MAN WU, YANG-WEI WANG and GUANG-DONG SUN \\ Department of Nephrology, The Second Hospital of Jilin University, Changchun, Jilin 130041, P.R. China
}

Received June 16, 2016; Accepted April 13, 2017

DOI: $10.3892 / \mathrm{etm} .2017 .4671$

\begin{abstract}
Hepatitis C virus (HCV) is a major cause of liver-associated morbidity and has an increasing prevalence worldwide. Hepatitis $\mathrm{C}$ virus infection may lead to chronic hepatitis, cirrhosis and liver failure. However, it is also associated with a wide range of extra-hepatic complications, such as cryoglobulinemia, an immune complex disease associated with cryoglobulin leading to multiple organ damage and, while the major symptom is vasculitis. The present study reported on a-58-year-old woman who was diagnosed with HCV-associated cryoglobulinemia with skin, kidney and blood system damage and biopsy-proven cryoglobulinemia membrano-proliferative glomerulonephritis. HCV RNA clearance occurred within a few weeks of interferon treatment and the patient was then treated by prednisolone and sustained interferon. While the therapeutic effect was obvious at first, the disease reappeared in combination with refractory infection and multiple organ failure, and the patient finally died. HCV-associated cryoglobulinemia is uncommon in developing countries such as China, while treatment guidelines remain to be established, particularly if complex complications are present.
\end{abstract}

\section{Introduction}

As medical knowledge evolved, the general awareness of the hepatitis $\mathrm{C}$ virus (HCV) has changed since its discovery, as it was not only considered as the etiological cause of chronic hepatitis, but also the cause of numerous HCV-associated diseases, particularly autoimmune diseases, such as cryoglobulinemia, Sjörgen's syndrome and arthritis (1). After HCV-associated cryoglobulinemia was reported for the first time, medical research has focused on it. In the past decade, numerous studies reported that a majority of cases of mixed

Correspondence to: Dr Guang-Dong Sun, Department of Nephrology, The Second Hospital of Jilin University, 218 Ziqiang Street, Nanguan, Changchun, Jilin 130041, P.R. China

E-mail: sungd@jlu.edu.cn

Key words: hepatitis $\mathrm{C}$ virus, cryoglobulinemia, treatment, membrano-proliferative glomerulonephritis cryoglobulinemia (MC) were associated with HCV (2). Although the underlying mechanisms have not been fully clarified, cryoglobulin formation is at least linked to chronic HCV infection (3). A total of 20-30\% of MC patients had renal involvement, mainly due to membranoproliferative glomerulonephritis (MPGN) (4). Therefore, treatments of these patients have mainly focused on the reduction of the viral load, the elimination of immune complexes and the function of B cells. Hence, the present case study presented a case diagnosed as MC with MPGN and its treatment, and summarized the diagnosis, clinical manifestations and treatments of MC with a particular focus on MC-associated renal injury.

\section{Case report}

Informed consent was provided by the patient's husband for her inclusion in the present study. A-58-year-old woman presented at the Department of Nephrology of the Second Hospital of Jilin University (Changchun, China) on December 17th 2012 with intermittent edema in the lower limbs that had persisted for eight months and proteinuria for one month, while purpura on the bilateral lower limbs had been present for five years (Fig. 1), which deteriorated in the cold. The patient's clinical and laboratory data at first presentation are listed in Table I. The qualitative cryoglobulin test was positive. Renal biopsy was performed and immunofluorescence results were as follows: Immunoglobulin ( $\operatorname{Ig}) \mathrm{A}(+/-), \operatorname{IgM}(+), \operatorname{IgG}(+)$, complement $\mathrm{C} 3(2+)$, complement $\mathrm{C} 4(-)$, complement factor $\mathrm{lq}(+)$ and fibrinogen(-). Light microscopic: Periodic Acid-Schiff staining revealed 37 intact glomeruli, parts of which were hypertrophic, and two sclerotic gomeruli, one of which displayed fibrous crescent formation. Glomerular mesangial cells and endothelial cells were diffuse with severe hyperplasia. Vacuolar degeneration of endothelial cells and microthrombosis in capillary lumens was observed, and most of the capillary loops were obstructed. Various renal tubular epithelial cells had degenerated with small focal atrophy and occasional protein casts. Renal interstitial edema, focal inflammation and inflammatory cell infiltration were present, particularly around blood vessels. Part of the wall of an arteriole was slightly thickened; Periodic Acid Methenamine Silver + Masson staining revealed a diffuse double track appearance without identifiable spikes, and endothelial and mesangial areas contained diffuse eosinophilic complexes with red staining (Fig. 2). The pathological 
Table I. Laboratory parameters at onset.

\begin{tabular}{lcc}
\hline Parameter & Value & $\begin{array}{c}\text { Normal } \\
\text { range }\end{array}$ \\
\hline White blood cells $\left(\mathrm{x} 10^{9} / \mathrm{l}\right)$ & 6.7 & $3.5-9.5$ \\
Haemoglobin $(\mathrm{g} / \mathrm{l})$ & 93 & $115-150$ \\
Platelet count $\left(\mathrm{x} 10^{9} / \mathrm{l}\right)$ & 207 & $125-350$ \\
Creatinine $(\mu \mathrm{mol} / \mathrm{l})$ & 76.9 & $44-106$ \\
Proteinuria/24 h $(\mathrm{g})$ & 3.65 & $<0.15$ \\
Albumin $(\mathrm{g} / \mathrm{l})$ & 22.5 & $40-55$ \\
HBsAg & Negative & $0-0.05$ \\
Anti-HBs & Negative & Negative \\
Anti-HBc & Negative & Negative \\
HCV-RNA $(\mathrm{IU} / \mathrm{ml})$ & $1.12 \times 10^{7}$ & $<1.0 \mathrm{e}^{2}$ \\
Rheumatoid factor $(\mathrm{IU} / \mathrm{ml})$ & 459.0 & $<20$ \\
Complement C4 $(\mathrm{mg} / \mathrm{dl})$ & $<1.67$ & $16-38$ \\
Complement C3 (mg/dl) & 91.6 & $79-152$ \\
ANA & Negative & $<1: 100$ \\
HIV & Negative & $0-1.0$ \\
Proteinuria & $3+$ & Negative \\
IgG $(\mathrm{g} / \mathrm{l})$ & 10.7 & $7.51-15.6$ \\
IgM $(\mathrm{g} / \mathrm{l})$ & 3.4 & $0.46-3.04$ \\
IgA $(\mathrm{g} / \mathrm{l})$ & 1.85 & $0.82-4.53$ \\
Erythrocyte sedimentation rate $(\mathrm{mm})$ & 74.0 & $<20$ \\
ANCA & Negative & Negative \\
\hline & & \\
\hline
\end{tabular}

Ig, immunoglobulin; HBsAg, hepatitis B surface antigen; HIV, human immunodeficiency virus; ANA, antinuclear antibody; HCV, hepatitis C virus; ANCA, antineutrophil cytoplasmic antibodies.

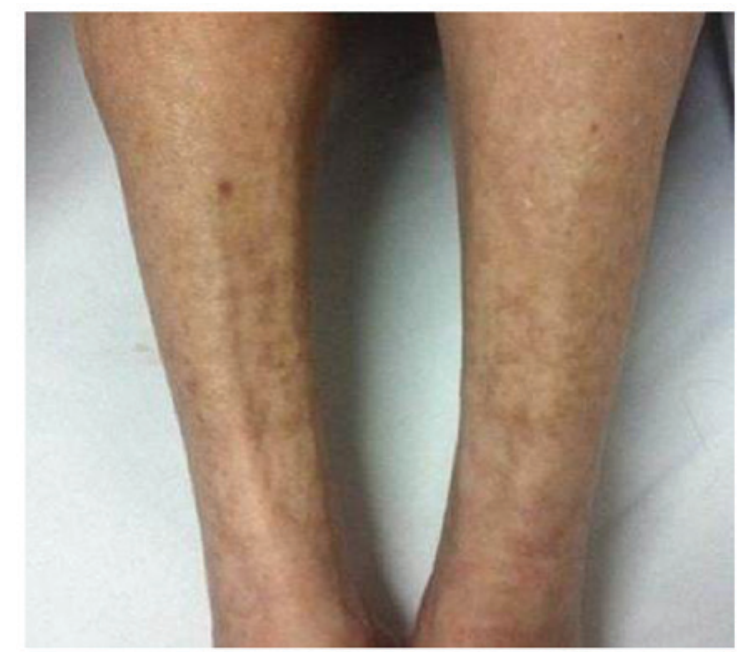

Figure 1. Purpura-shaped pigmentation in bilateral lower limbs.

diagnosis was mesangial proliferative glomerulonephritis (HCV-associated cryoglobulinemia) with a possibility of MPGN. Based on all of these results and the quantity of HCV RNA, the patient was given interferon $\alpha(500,000$ IU every other day) by subcutaneous injection from December 19th 2012 until the quantity of HCV RNA reached below the minimum on January 30th 2013. Subsequently, the patient was treated with prednisolone (40 mg daily) and continued to use interferon $\alpha$. In response to this treatment, the results of continuous examinations of the liver, kidney function, blood, routine urine, 24-h proteinuria and the load of HCV RNA remained steady. The patient's $24-\mathrm{h}$ proteinuria was reduced to $1.95 \mathrm{~g}$ after three months and continued to take oral prednisolone and interferon $\alpha$ without the occurrence of any edema. Therefore, prednisolone was gradually reduced, while interferon $\alpha$ treatment was continued.

The patient presented at our department for the second time on August 30th 2013 due to elevated axillary temperature $\left(>37.2^{\circ} \mathrm{C}\right)$ for 15 days and after using interferon $\alpha$; further symptoms, including cough, expectoration, abdominal pain, diarrhea as well as increased urinary frequency and urgency, were not present. Clinical examination revealed an axillary temperature of $38^{\circ} \mathrm{C}$ and a blood pressure of $160 / 80 \mathrm{mmHg}$, and findings of the heart, lung and abdominal examination were unremarkable. The bilateral lower limbs showed a large tract of purpura without tenderness and edema. Laboratory parameters were as follows (normal ranges in brackets): Albumin (40-55 g/l), $40.2 \mathrm{~g} / \mathrm{l}$; creatinine $(44-106 \mu \mathrm{mol} / \mathrm{l}), 81.8 \mu \mathrm{mol} / \mathrm{l}$; blood leukocytes $\left(3.5-9.510^{9}\right.$ cells/1), $18.3 \times 10^{9}$ cells $/ 1$; hemoglobin (115-150 g/l), $108 \mathrm{~g} / \mathrm{l}$; platelets $\left(125-350 \times 10^{9}\right.$ cells/l), $154 \times 10^{9}$ cells/l; urine protein (negative), 2+; urine leucocytes [0-5/high power field (HPF)], 81.3/HPF. Chest computed tomography showed tracheitis. Abdominal doppler ultrasound was normal. The load of HCV was always below the minimum value. These results were unlikely to be due to prednisolone intake, while the use of interferon $\alpha$ may have caused the fever; it was therefore discontinued and anti-inflammatory therapy (linezolid, $0.6 \mathrm{~g}$ twice daily; meropenem, $1.0 \mathrm{~g}$ twice daily; and micafungin, $0.15 \mathrm{~g}$ once daily, all intravenous) was commenced. The temperature was consistently $>39^{\circ} \mathrm{C}$ and returned to normal values after 2 days. However, the whole blood cell count decreased significantly, while serum creatinine increased and oliguria occurred, and the patient died of multiple organ dysfunction syndrome on November 22nd 2013.

\section{Discussion}

MC-associated glomerulonephritis is the most important extrahepatic manifestation of chronic HCV infection, but its prognosis is poor. Furthermore, as unified treatment guidelines are currently lacking, a comprehensive and rigorous assessment of each patient is required, based on which a reasonable treatment is selected and changes of the disease require monitoring, particularly when various drugs are used in combination.

$\mathrm{HCV}$ has been considered as the major etiological cause of non-A and -B chronic hepatitis since its discovery in 1989; furthermore, clinical and experimental studies showed that $\mathrm{HCV}$ may cause certain autoimmune diseases, such as MC and Sjörgen's syndrome (1). While it has been reported that $\sim 1 / 3$ of $\mathrm{HCV}$-associated $\mathrm{MC}$ was accompanied with renal damage (5), this rarely occurs in China, only few case reports (6). Tarantino et al (7) postulated the following major clinical diagnostic criteria: i) Cryoglobulin present in serum; ii) hematuria, proteinuria and renal damage; and iii) renal biopsy pathology consistent with the pathological characteristics of cryoglobulinemia nephropathy. Other minor clinical features 


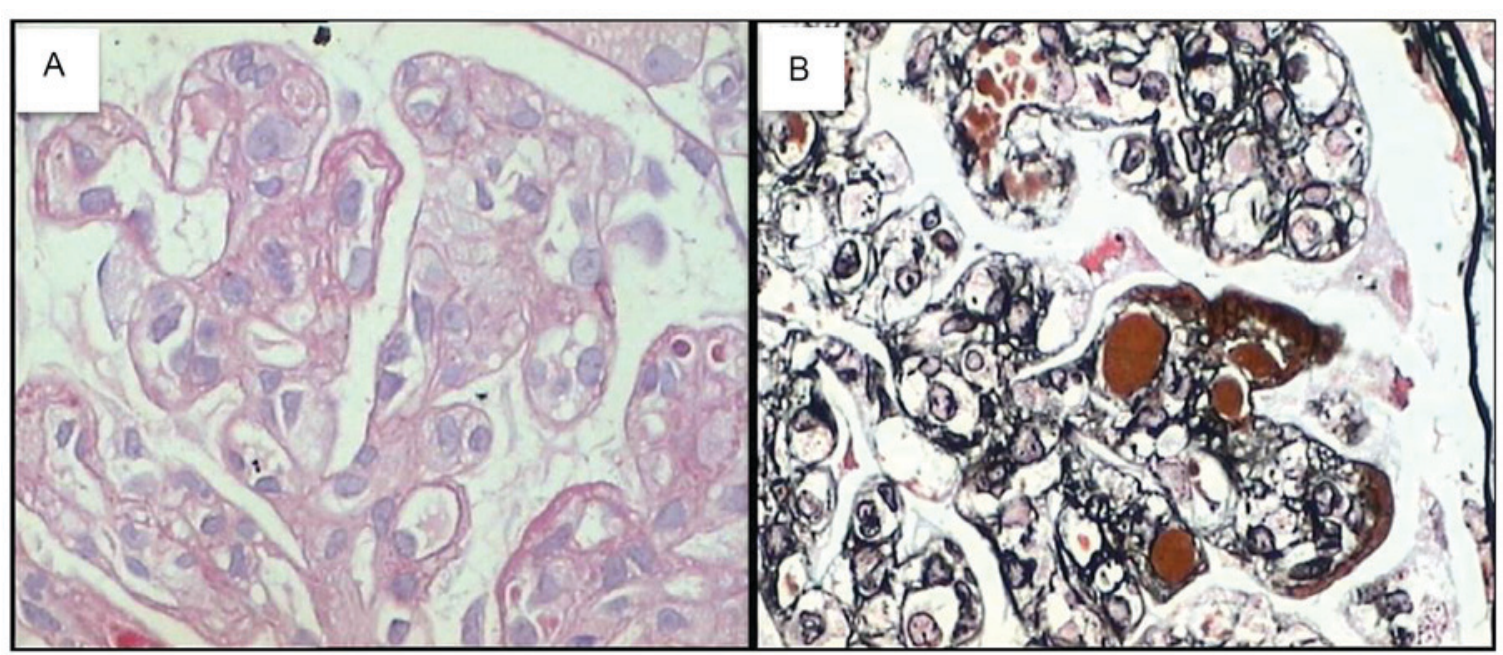

Figure 2. Histopathology images of renal tissues displaying glomeruli. (A) Periodic Acid-Schiff staining; (B) Periodic Acid Methenamine Sliver staining (magnification, $\mathrm{x} 400$ ).

such as purpura and rheumatoid factor may also be considered. The quantitative determination of cryoglobuline is of high importance. However, due to the limitations of our hospital, only qualitative detection was possible. Combined with the pathological results, clinical manifestations and auxiliary examination, the diagnosis of cryoglobulinemia was established.

As cryolobulinemia is vasculitis in its essence, it may involve multiple organs. The deposition of cryoglobulins and complement leads to diverse pathological manifestations, including purpura, skin ulcers and glomerulonephritis. The most common symptoms of MC are weakness, peripheral neuropathy, arthralgias and purpura (Meltzer and Franklin triad), Raynaud's phenomenon, sicca syndrome, renal involvement, lung disorders, elevated axillary temperature $>37.2^{\circ} \mathrm{C}$ and hematocytopenia. The frequent manifestations of $\mathrm{MC}$ are peripheral neuropathy and skin ulcers, which are barely responsive to treatments and may consequently compromise the patient's quality of life. The association between cryoglobulinemia and glomerulonephritis has been demonstrated (8). In previous studies, $20 \%$ of patients with MC were diagnosed with nephropathy, which even increased to $35-60 \%$ during the follow-up period, and renal injury is one of the factors associated with the worst prognosis of MC patients $(8,9)$. MC-associated nephropathy is clinically characterized by hematuria, proteinuria, edema and renal failure. The pathology is similar to MPGN, but histological examination of renal biopsy specimens revealed cryoglobulin thrombi in the capillaries. Clinical studies have shown that MC patients often present with one or more subclinical signs of renal involvement, including asymptomatic hematuria, nephrotic syndrome, nephrotic proteinuria $(<3 \mathrm{~g} / 24 \mathrm{~h})$, or only renal dysfunction (10). A total of $30 \%$ of patients may present with acute nephrotic syndrome (11). Nearly $15 \%$ of patients progressed to terminal chronic renal failure, even requiring dialysis (12). Certain examinations are important; the obvious reduction or undetectable levels of complement $\mathrm{C} 4$ are another hallmark of the disease and is particularly useful for disease classification, while the activity/severity of cryoglobulinemia is rarely correlated with the complement C4 level. However, they are not appropriate for clinical monitoring of patients and therapeutic decision-making.

The treatment of HCV-associated MC is particularly based on the complex pathogeny and clinical manifestations of the disease. In fact, MC may be treated at three different levels; type I cryoglobulinemia, type II cryoglobulinemia and type III cryoglobulinemia. The principles for treating MC are as follows: i) If no symptoms of cryoglobulinemia are present, no treatment is applied; ii) secondary cryoglobulinemia is mainly managed by treating the primary disease; iii) if only joint symptoms are present, non-steroid anti-inflammatory drugs are given; iv) corticosteroids and immunosuppressive agents are suitable for patients with serious illness and visceral injury; and v) plasma exchange for severe disease (13). Studies have suggested that low doses of interleukin 2 are suitable for treating HCV-associated cryoglobulinemia. The treatment of HCV infection-associated symptoms mainly comprises anti-viral therapy, but guidelines regarding the best anti-viral treatment of these patients remain to be established. The current options are pegylated interferon $\alpha$ and ribavirin, which are applied according to the type and the quantity of HCV. Thus, rituximab has been used as an agent to treat $\mathrm{HCV}$-associated autoimmune diseases according to B-cell lymphoproliferation (14-16). The patient of the present study was a typical case of cryoglobulinemia and renal damage secondary to HCV infection; prednisolone combined with interferon therapy was initially effective, while multiple organ failure and death eventually occurred. As cryoglobulinemia is essentially vasculitis, it ultimately causes multiple organ damage, and the prognosis of patients with renal damage caused by HCV is therefore poor. Despite of the early treatment with prednisolone and interferon being effective, it easily induces refractory infections.

In conclusion, the present study found that $\mathrm{HCV}$-associated cryoglobulinemia with MPGN treated with prednisolone and interferon $\alpha$ is effective; however, monitoring of the patient focused on the drugs' effects, while side effects wereignored. Therefore, the present case study provided experience for future treatments and it is suggested that clinical studies are required to identify the most appropriate treatment strategies. 


\section{References}

1. Ferri C, Antonelli A, Mascia MT, Sebastiani M, Fallahi P, Ferrari D, Pileri SA and Zignego AL: HCV-related autoimmune and neoplastic disorders: The HCV syndrome. Dig Liver Dis 39 (Suppl 1): 13-21, 2007.

2. Dammacco F and Sansonno D: Antibodies to hepatitis C virus in essential mixed cryoglobulinaemia. Clin Exp Immunol 87: 352-356, 1992.

3. Neumann AU, Lam NP, Dahari H, Gretch DR, Wiley TE, Layden TJ and Perelson AS: Hepatitis C viral dynamics in vivo and the antiviral efficacy of interferon-a therapy. Science 282: 103-107, 1998.

4. Dammacco F, Sansonno D, Piccoli C, Tucci FA and Racanelli V: The cryoglobulins: An overview. Eur J Clin Invest 31: 628-638, 2001.

5. lannuzzella F, Vaglio A and Garini G: Management of hepatitis C virus-related mixed cryoglobulinemia. Am J Med 123: 400-408, 2010.

6. Zhao LJ, Chen F, Li JG, Yin R, Zhang XH, Huang SM and Liu F: Hepatitis $C$ virus-related mixed cryoglobulinemic endocapillary proliferative glomerulonephritis and B-cell non-Hodgkin lymphoma: A case report and literature review. Eur Rev Med Pharmacol Sci 19: 3050-3055, 2015.

7. Tarantino A, De Vecchi A, Montagnino G, Imbasciati E, Mihatsch MJ, Zollinger HU, Di Belgiojoso GB, Busnach G and Ponticeli C: Renal disease in essential mixed cryoglobulinaemia. Long-term follow-up of 44 patients. Q J Med 50: 1-30, 1981.

8. Daghestani L and Pomeroy C: Renal manifestations of hepatitis C infection. Am J Med 106: 347-354, 1999.
9. Ferri C, Sebastiani M, Giuggioli D, Cazzato M, Longombardo G, Antonelli A, Puccini R, Michelassi C and Zignego AL: Mixed cryoglobulinemia: Demographic, clinical and serologic features and survival in 231 patients. Semin Arthritis Rheum 33: 355-374, 2004.

10. Ozkok A and Yildiz A: Hepatitis $\mathrm{C}$ virus associated glomerulopathies. World J Gastroenterol 20: 7544-7554, 2014.

11. Misiani R, Bellavita P, Fenili D, Borelli G, Marchesi D, Massazza M, Vendramin G, Comotti B, Tanzi E, Scudeller G, et al: Hepatitis $\mathrm{C}$ virus infection in patients with essential mixed cryoglobulinemia. Ann Intern Med 117: 573-577, 1992.

12. Tarantino A, Campise M, Banfi G, Conflalonieri R, Bucci A, Montonli A, Cloasanti G, Damilano I, D'Amico G, Minetti L, et al: Long-term predictors of survival in essential mixed cryoglobulinemic glomerulonephritis. Kidney Int 47: 618-623, 1995.

13. Bhattarai M, Woytowitz DV, Kaldash H, Bastacky S, Chen SS, Johnston JR and Bernardo JF: Recurrent mixed cryoglobulinemia (MCS): A case report and literature review. R I Med J (2013) 98: 33-37, 2015

14. De Vita S and Quartuccio L: Treatment of rheumatoid arthritis with rituximab: An update and possible indications. Autoimmun Rev 5: 443-448, 2006.

15. Grillo-López AJ, Hedrick E, Rashford M and Benyunes M: Rituximab: Ongoing and future clinical development. Semin Oncol 29 (1 Suppl 2): 105-112, 2002.

16. Patel DD: B cell-ablative therapy for the treatment of autoimmune diseases. Arthritis Rheum 46: 1984-1985, 2002. 